\title{
Imaging approach to COVID-19 Associated Pulmonary Embolism
}

Lukas Trunz ${ }^{1}$, Patrick Lee ${ }^{1}$, Steven Lange ${ }^{1}$, Corbin Pomeranz ${ }^{1}$, Laurence Needleman ${ }^{1}$, Robert Ford $^{1}$, Ajit Karambelkar ${ }^{1}$, and Baskaran Sundaram ${ }^{1}$

\section{${ }^{1}$ Thomas Jefferson University Hospital}

March 26, 2021

\begin{abstract}
The novel coronavirus disease-2019 (COVID-19) illness and deaths, caused by the severe acute respiratory syndrome coronavirus2, continue to increase. Multiple reports highlight the thromboembolic complications, such as pulmonary embolism (PE), in COVID-19. Imaging plays an essential role in the diagnosis and management of COVID-19 patients with PE. There continues to be a rapid evolution of knowledge related to COVID-19 associated PE. This review summarizes the current understanding of prevalence, pathophysiology, role of diagnostic imaging modalities, and management, including catheter-directed therapy for COVID-19 associated PE. It also describes infection control considerations for the radiology department while providing care for patients with COVID-19 associated PE.
\end{abstract}

\section{Hosted file}

Manuscript.pdf available at https://authorea.com/users/404164/articles/515438-imagingapproach-to-covid-19-associated-pulmonary-embolism

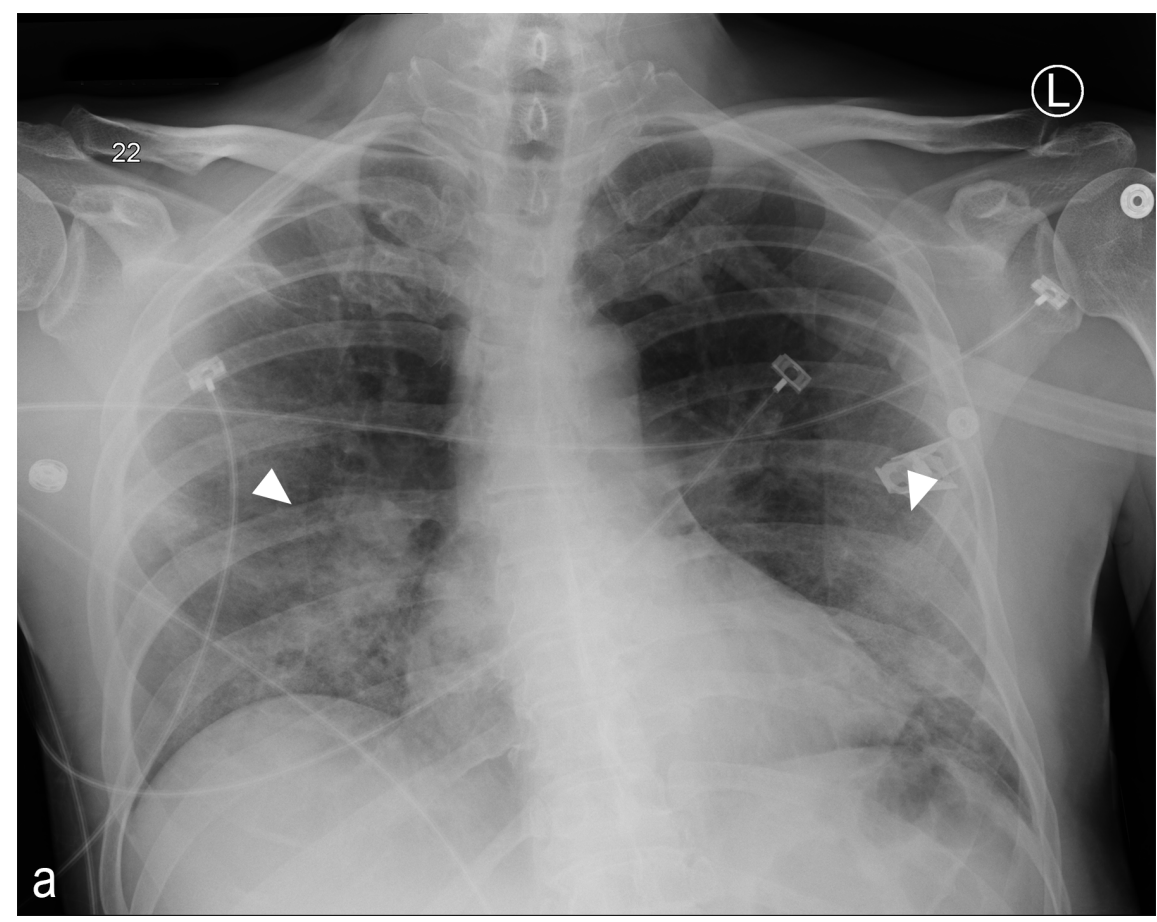



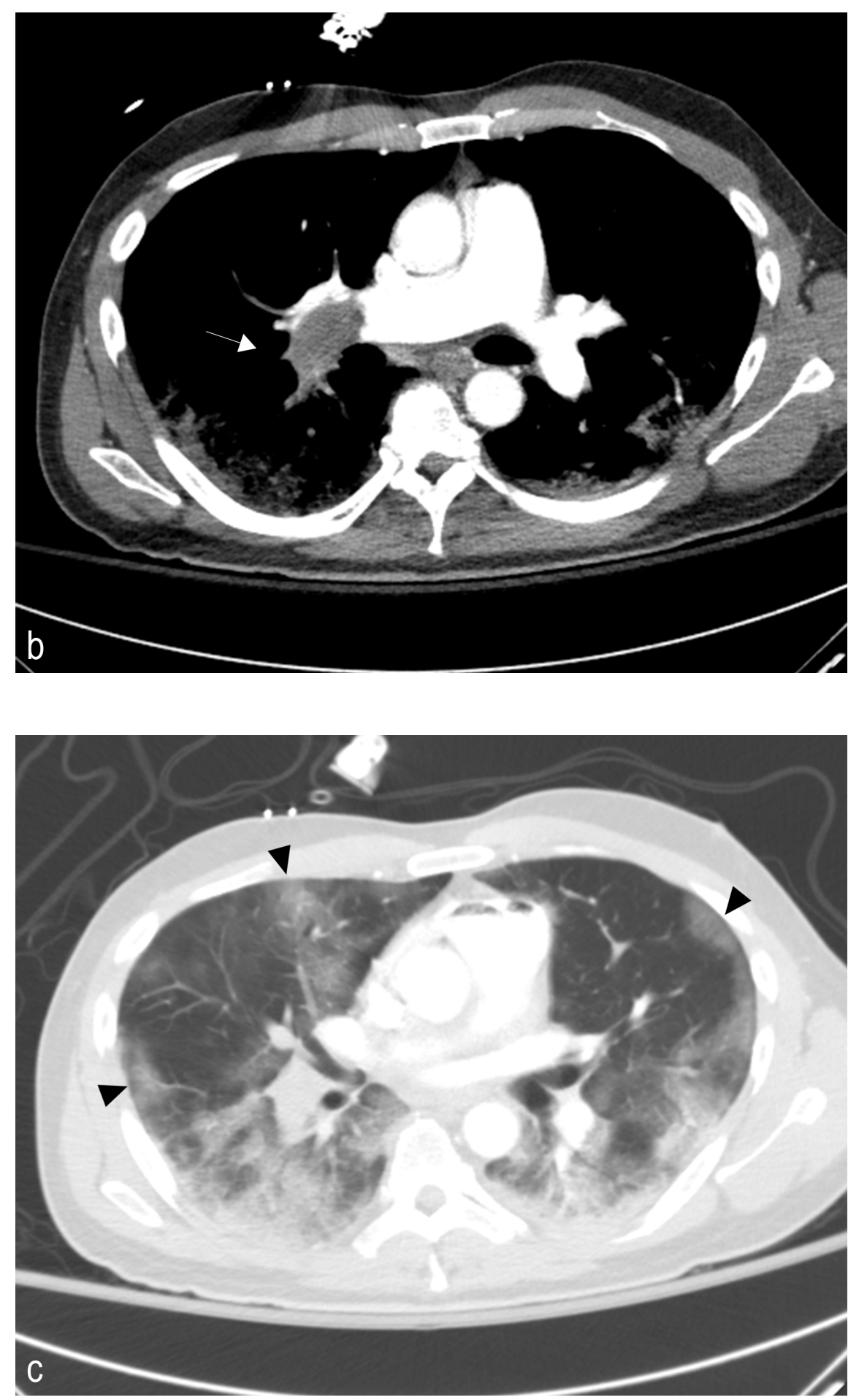

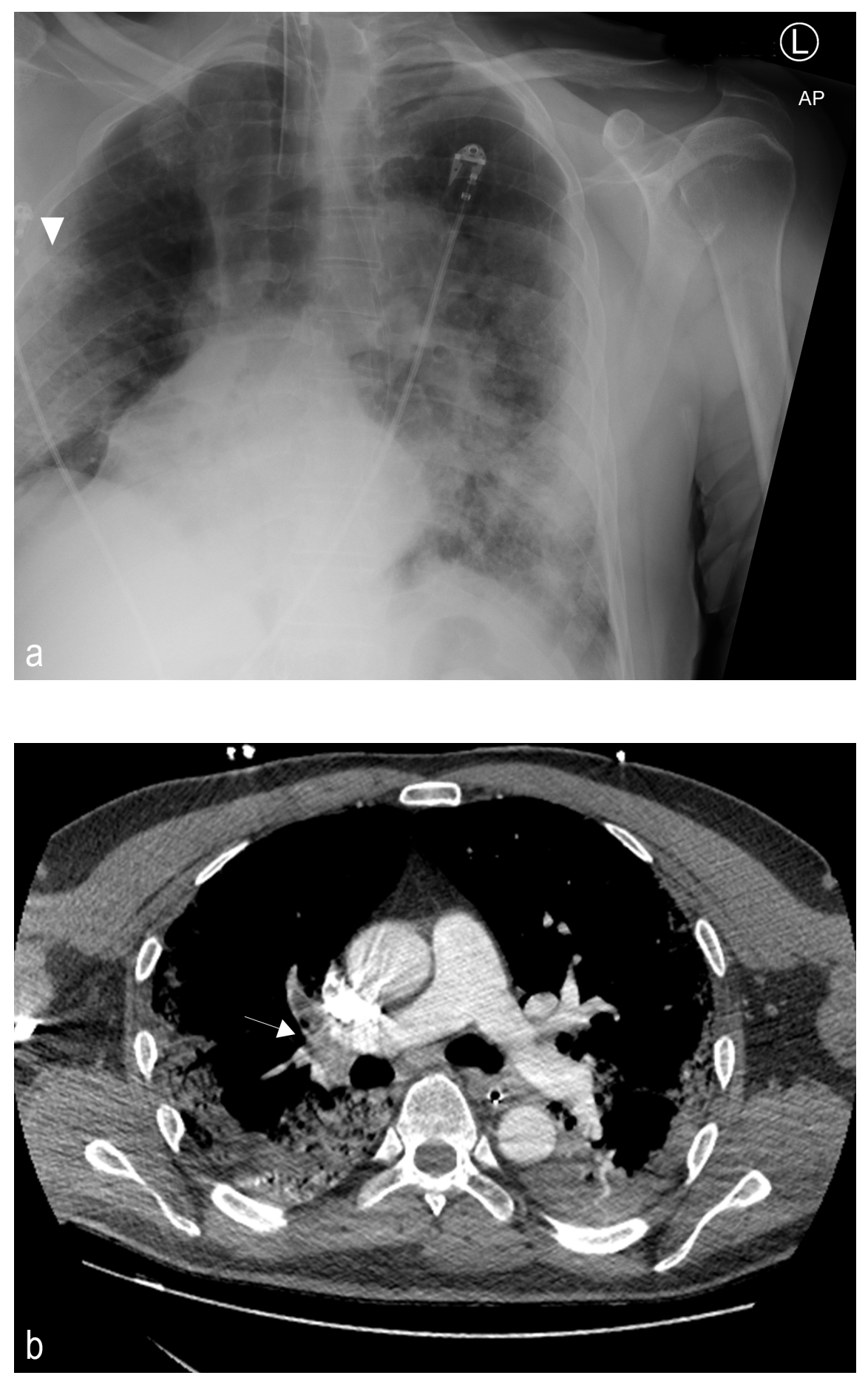

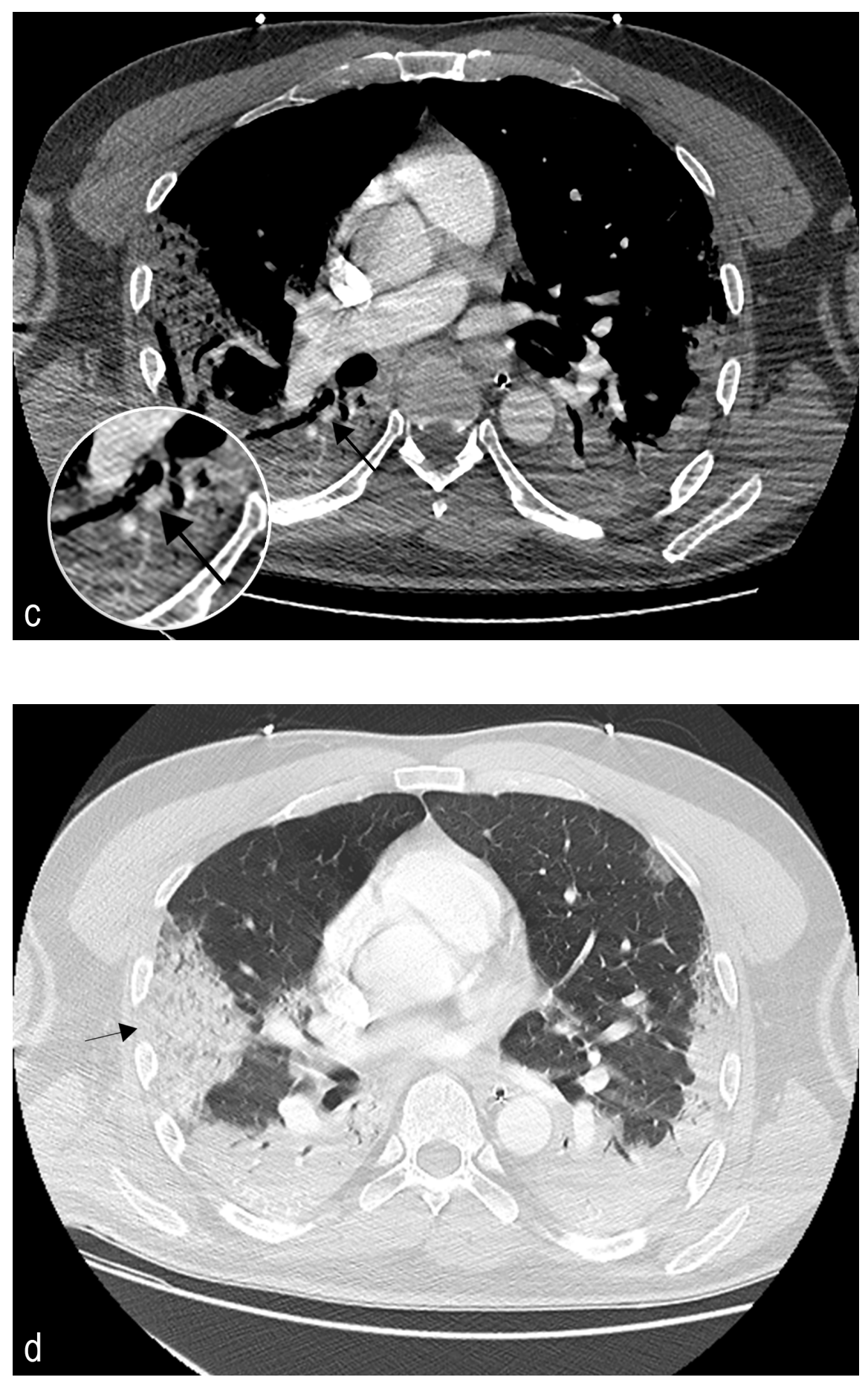

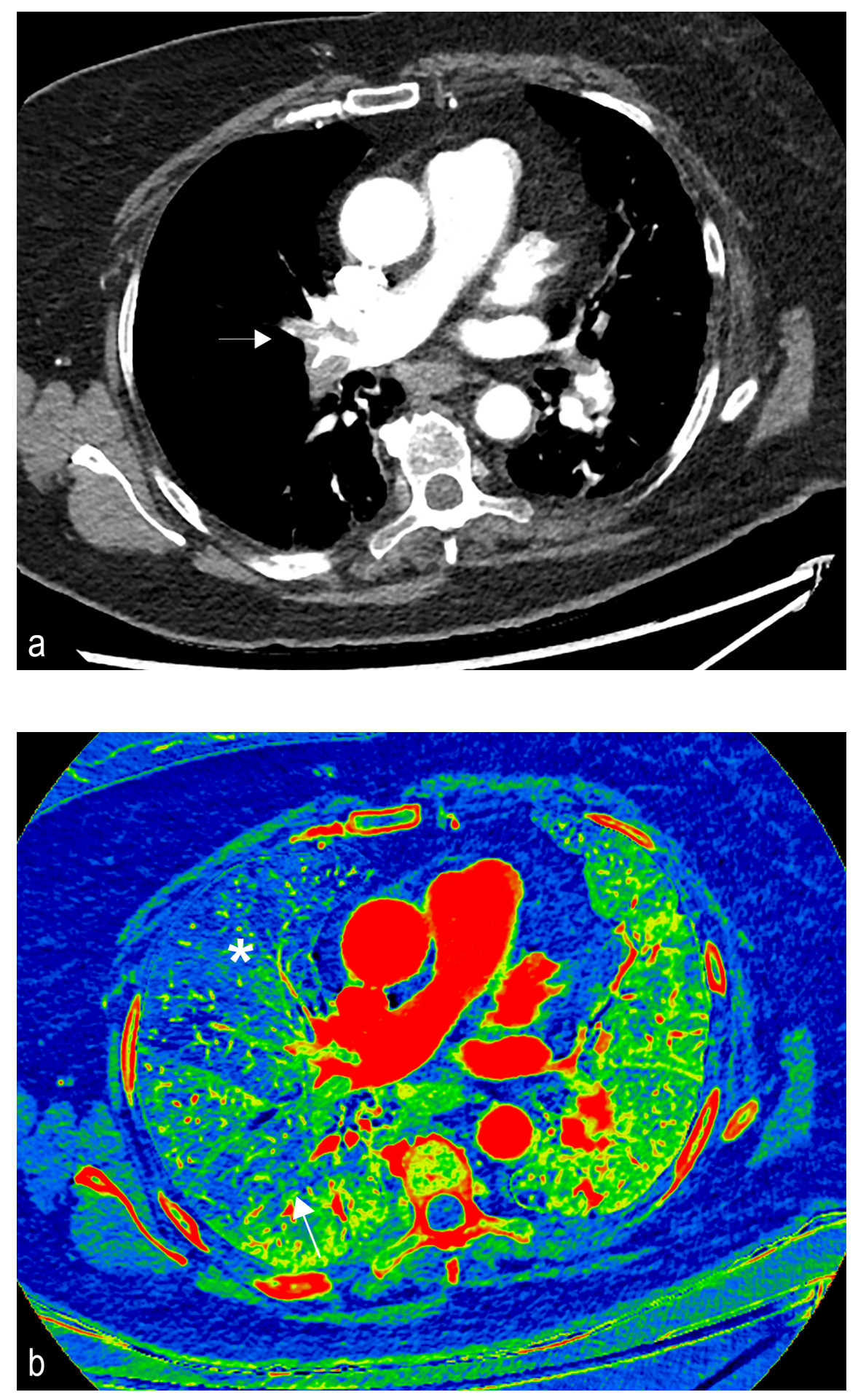

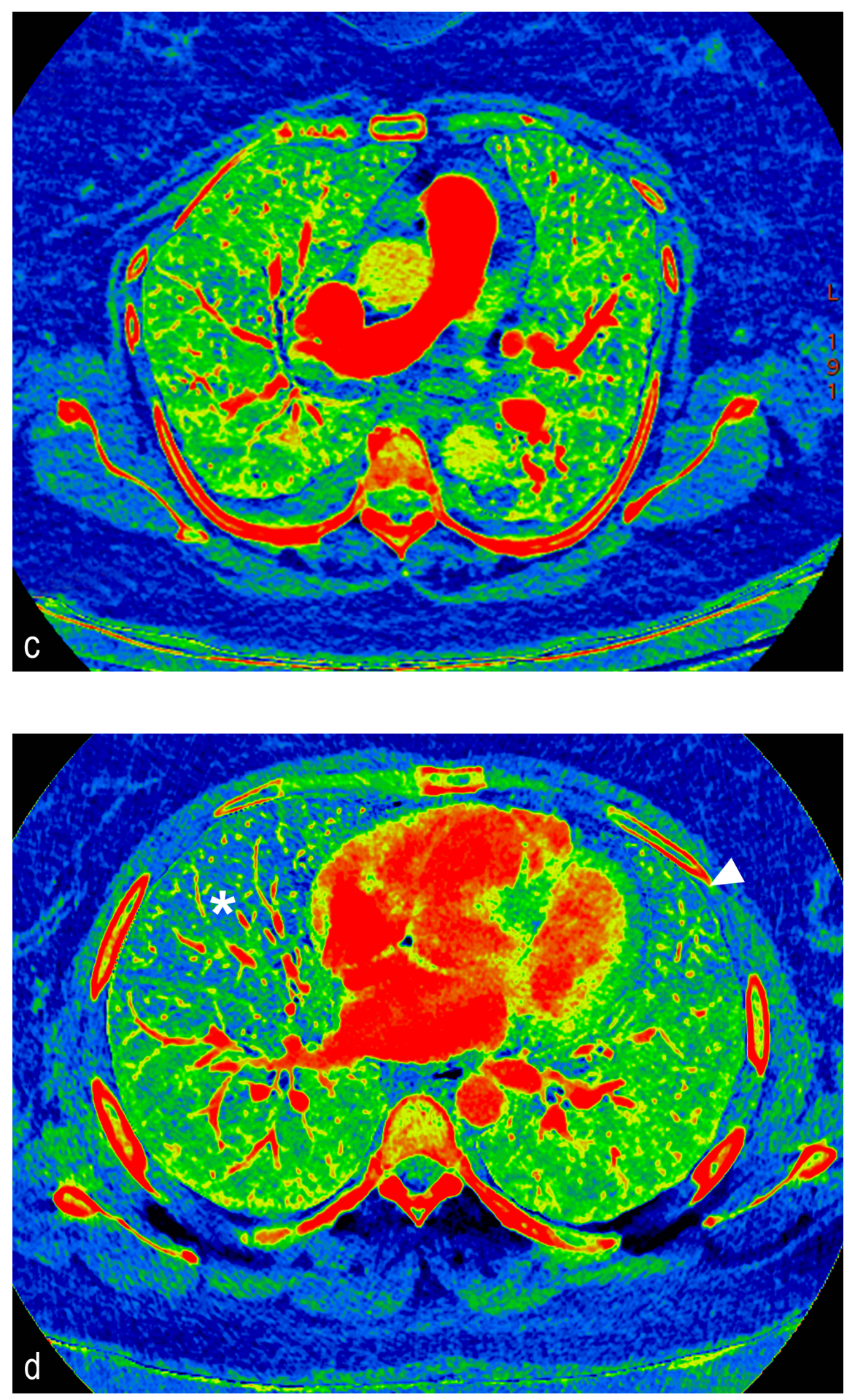


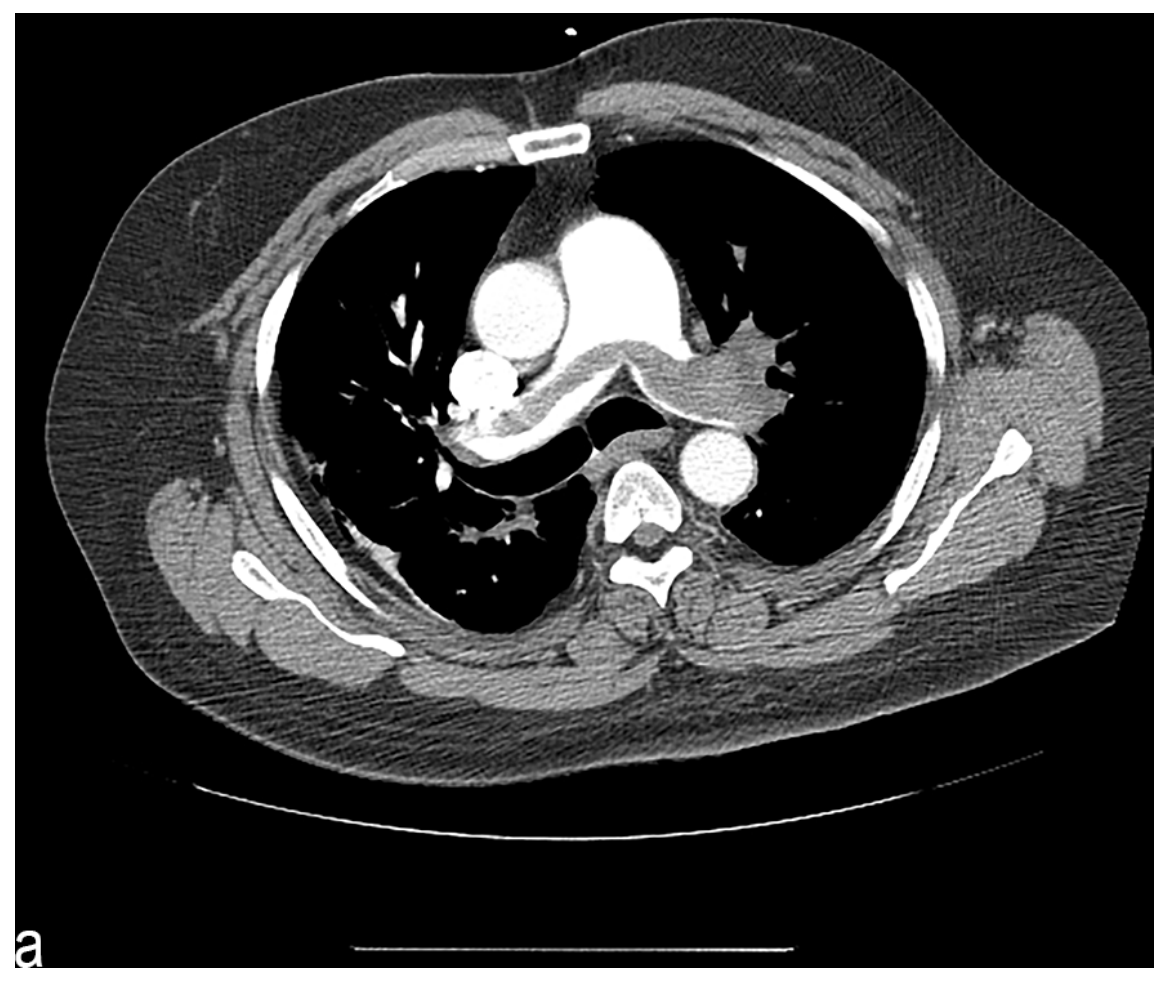




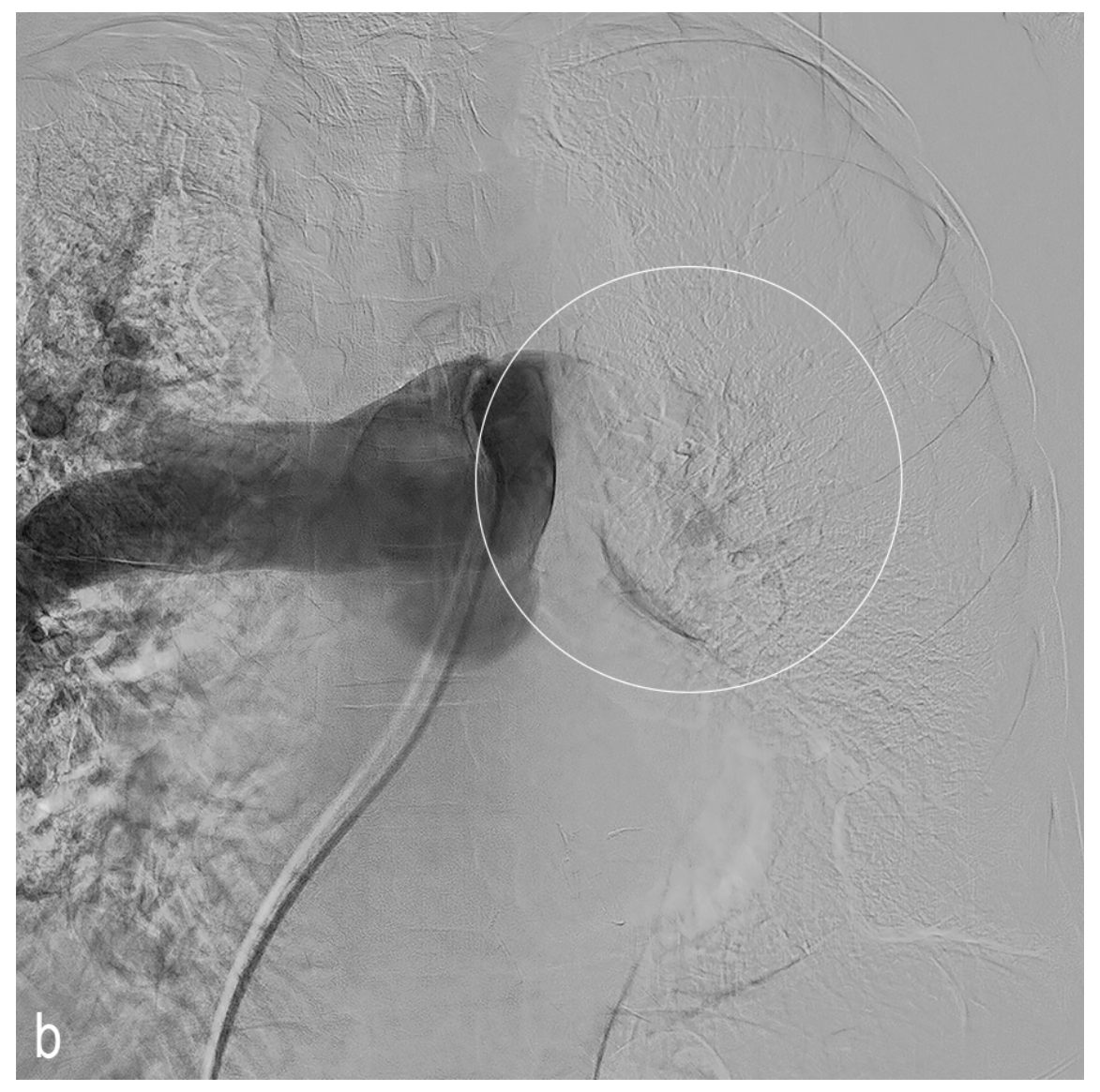




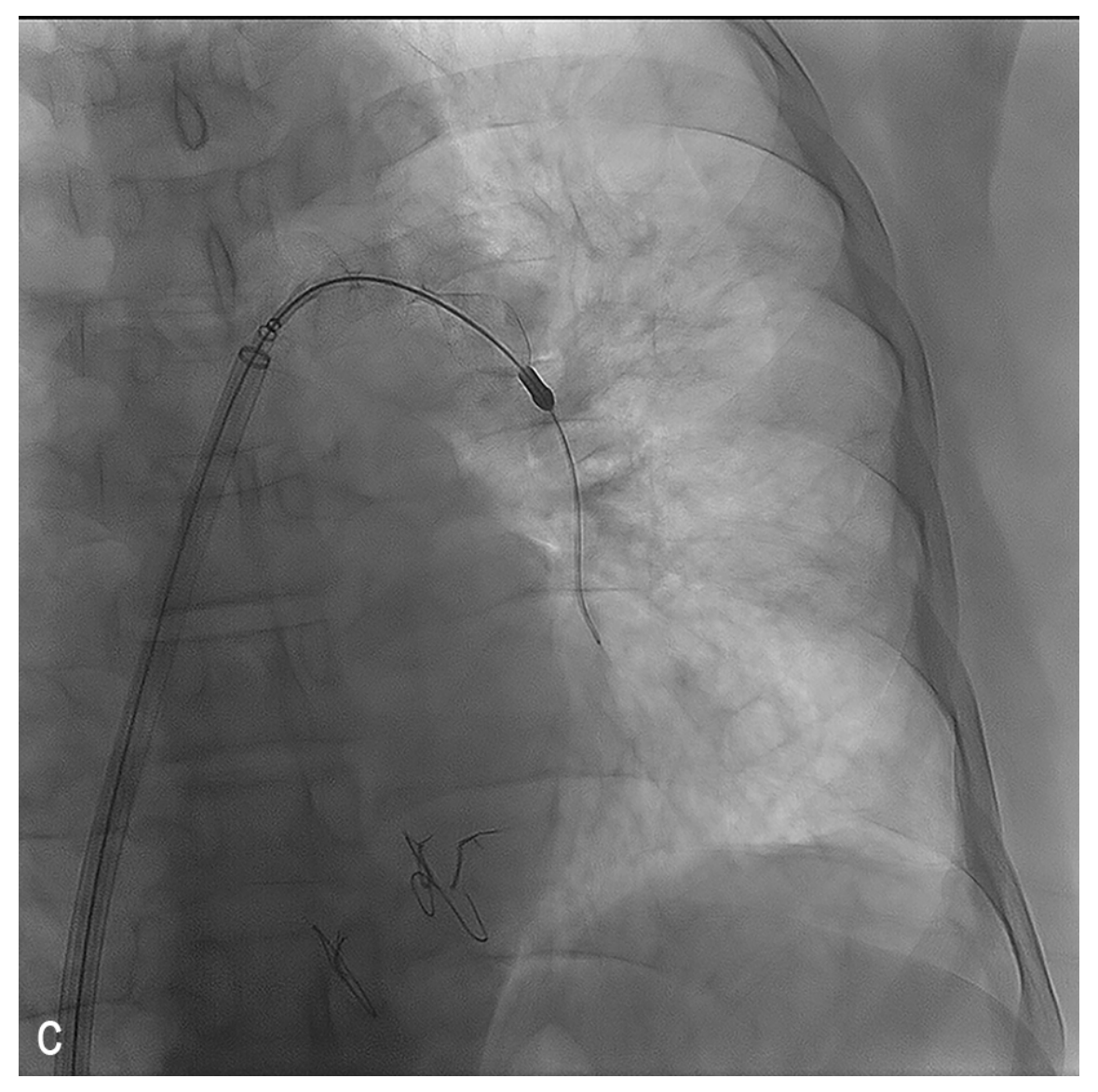




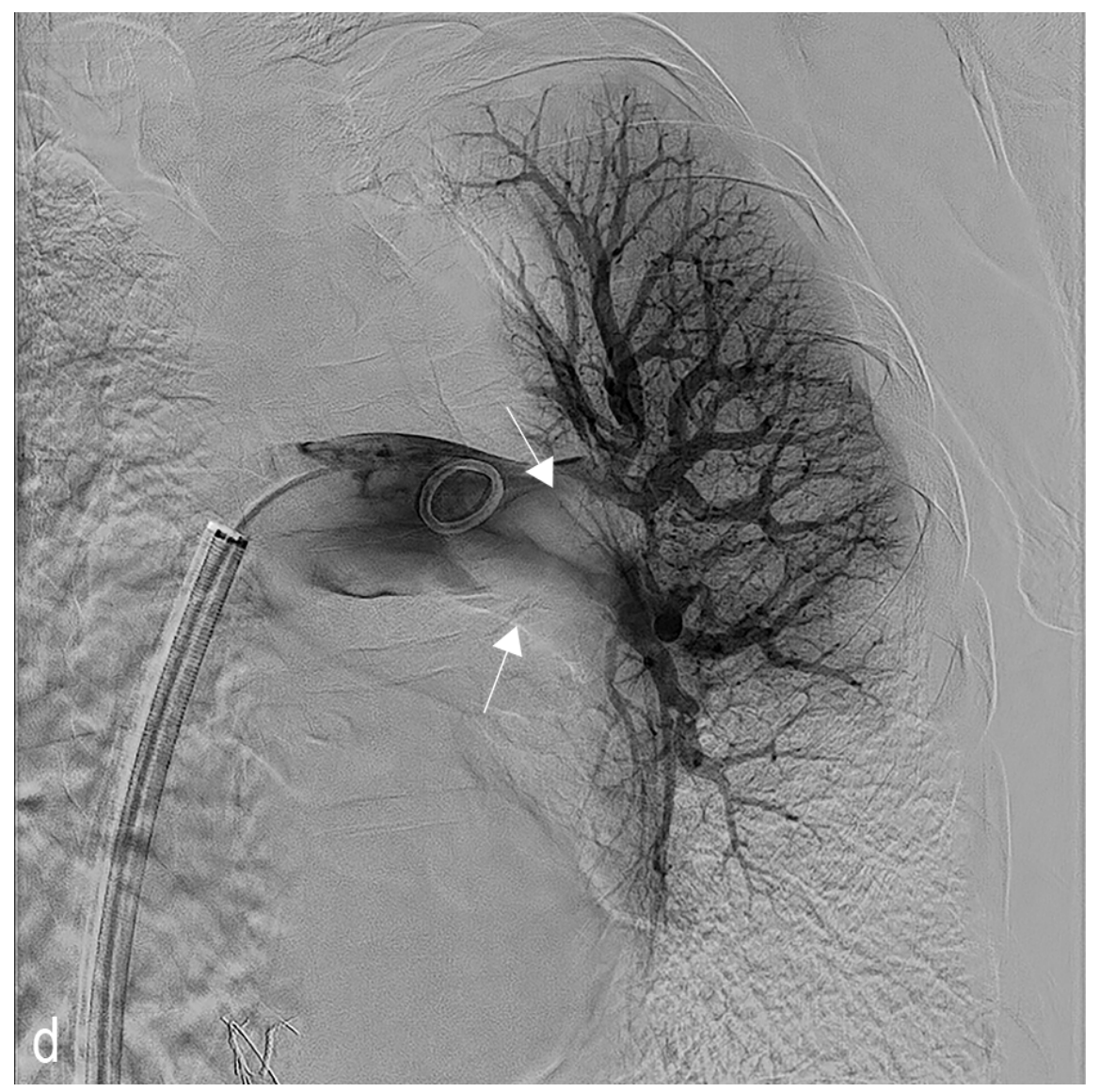




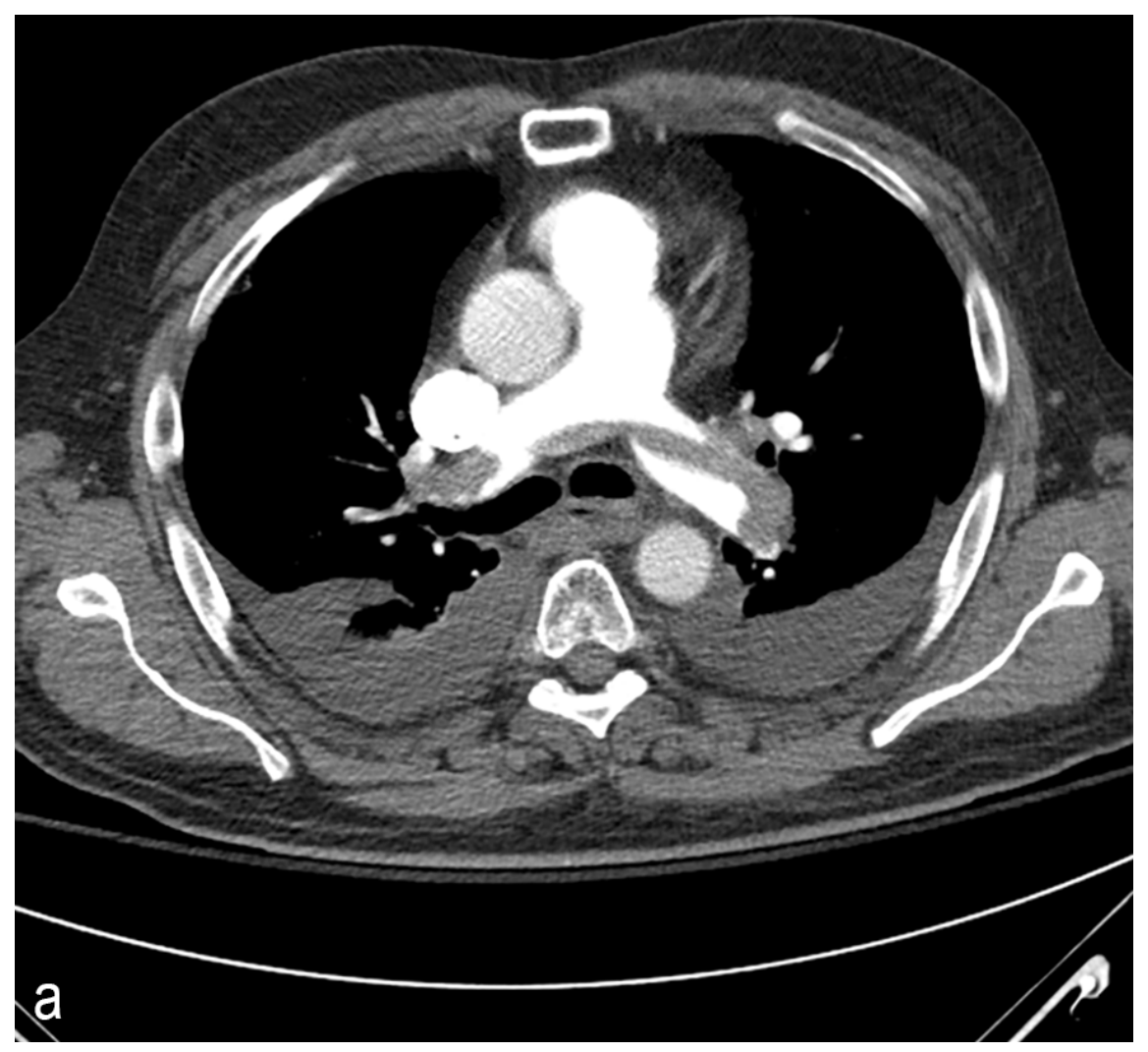




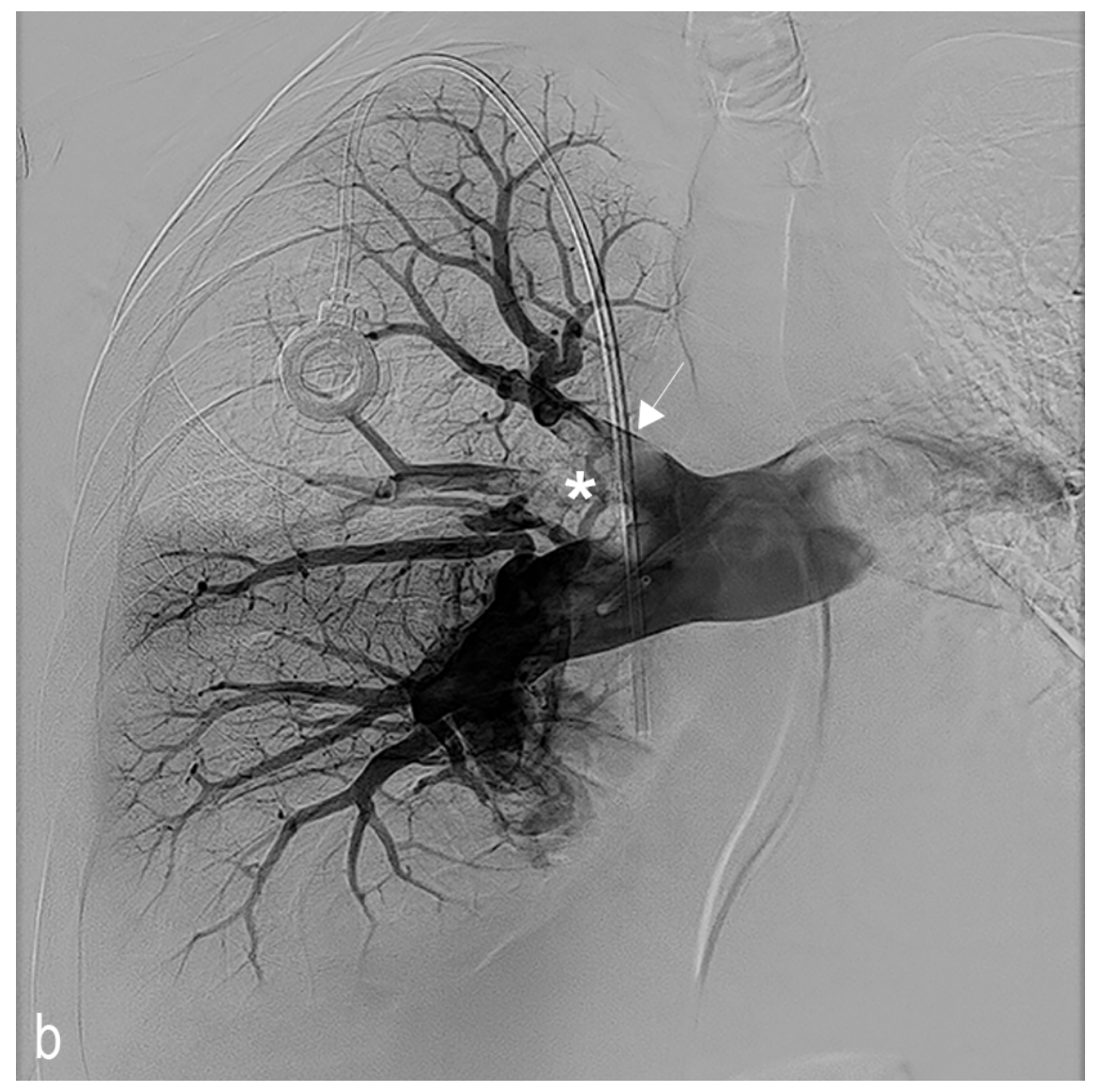




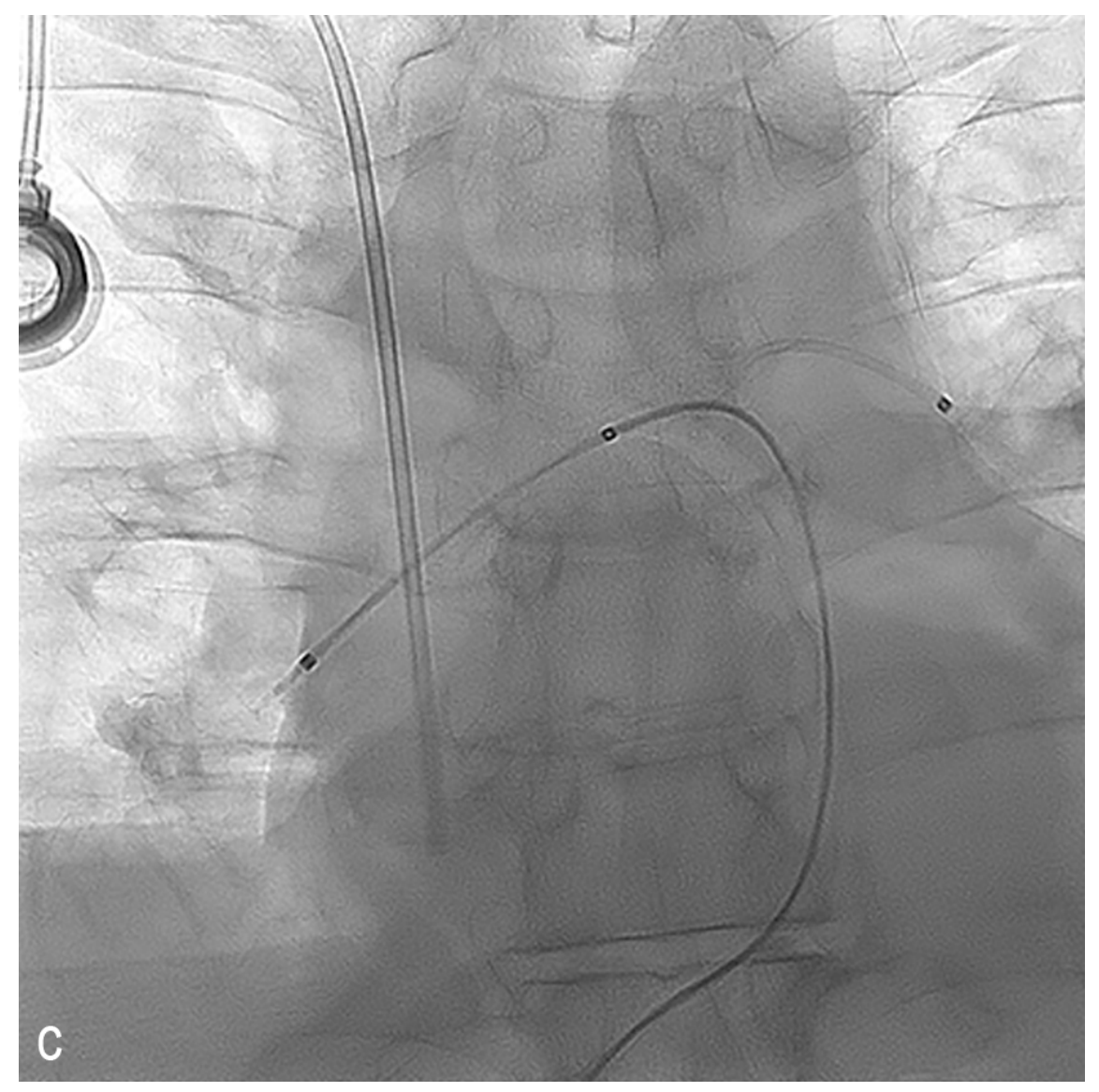




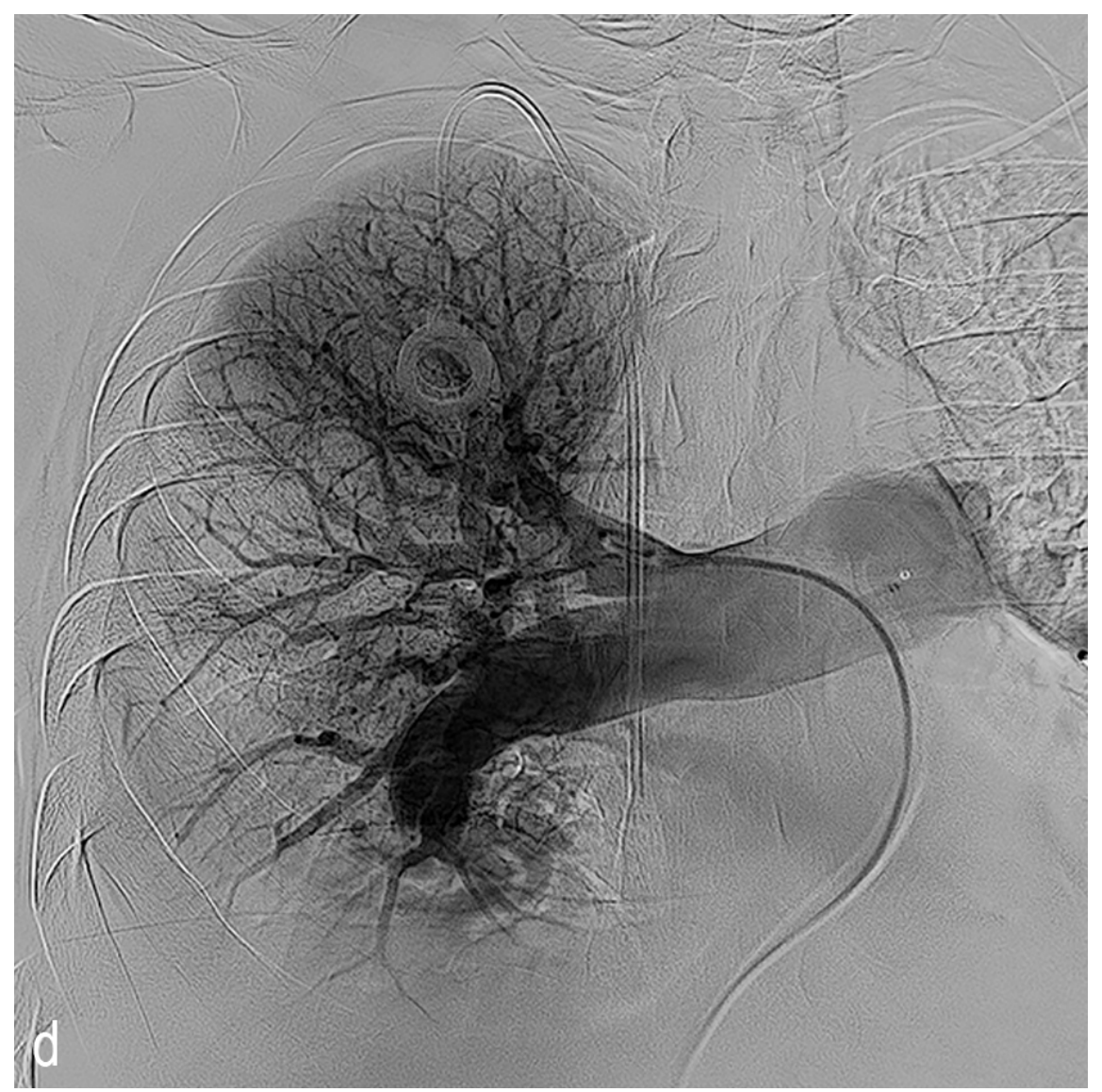

\section{Hosted file}

Table 1.pdf available at https://authorea.com/users/404164/articles/515438-imaging-approachto-covid-19-associated-pulmonary-embolism

\section{Hosted file}

Table 2.pdf available at https://authorea.com/users/404164/articles/515438-imaging-approachto-covid-19-associated-pulmonary-embolism 